\title{
A RETROSPECTIVE CLINICAL STUDY OF PATIENTS PRESENTING WITH EPISTAXIS IN A TERTIARY CARE HOSPITAL
}

Ravi $D^{1}$, Hanumanth Prasad $M^{2}$, Madhuri M. Gudikote ${ }^{3}$ Balaji N. $K^{4}$, Sowmya T. R ${ }^{5}$, Ravi Ambewadi ${ }^{6}$

${ }_{1}^{1}$ Associate Professor, Department of ENT, MIMS, Mandya.

2 Professor and HOD, Department of ENT, MIMS, Mandya.

3Junior Resident, Department of ENT, MIMS, Mandya.

${ }^{4}$ Assistant Professor, Department of ENT, MIMS, Mandya.

${ }^{5}$ Senior Resident, Department of ENT, MIMS, Mandya.

6Junior Resident, Department of ENT, MIMS, Mandya.

\section{BACKGROUND}

\section{ABSTRACT}

Epistaxis is one of the most common emergencies seen in Otorhinolaryngology. It is usually managed with simple conservative measures, but occasionally it can be a life-threatening condition. Immediate action and thorough evaluation is required to effectively manage a case of epistaxis.

The objectives of this study are-

1. To analyse the various aetiological factors for epistaxis.

2. To study the examination findings and investigations in relation to epistaxis.

3. To study the methods of management of epistaxis and their outcome in a tertiary care hospital.

\section{MATERIALS AND METHODS}

A retrospective descriptive study from Jan 2016 to Dec 2016 involving patients presenting with epistaxis was done in a tertiary care hospital, Mandya Institute of Medical Sciences, Mandya.

\section{RESULTS}

A total of 47 patients were included in this study; 32 were males and 15 were females. The most common cause of epistaxis was hypertension (61.70\%) followed by idiopathic (23.40\%) and coagulopathy secondary to liver disease (10.63\%). Regarding treatment methods, most of our patients required anterior nasal packing (82.97\%). Epistaxis was controlled by conservative methods in $76.59 \%$ patients. Surgical methods were considered for the rest of the patients. One patient required fresh frozen plasma transfusion for control of epistaxis secondary to coagulopathy.

\section{CONCLUSION}

Excluding trauma, hypertension and coagulopathy secondary to liver disease were the most common aetiological factors among the patients in this study in whom aetiology was found. Anterior epistaxis was more common than posterior epistaxis. Anterior nasal packing was the most common treatment method used in these patients.

\section{KEYWORDS}

Epistaxis, Hypertension, Electrocautery.

HOW TO CITE THIS ARTICLE: Ravi D, Prasad HM, Gudikote MM, et al. A retrospective clinical study of patients presenting with epistaxis in a tertiary care hospital. J. Evolution Med. Dent. Sci. 2018;7(03):298-301, DOI: 10.14260/jemds/2018/66

\section{BACKGROUND}

Epistaxis is defined as bleeding from the nose. ${ }^{1}$ Nasal bleeding is a common occurrence in otorhinolaryngology (ENT). It has been estimated that $60 \%$ of the population has at least one episode of epistaxis in their lifetime, of which $6 \%$ seek medical treatment. 2 There is a pronounced bimodal distribution in the age of onset of epistaxis, common in childhood, becomes less common in early adult life and then peaks in the sixth decade. $70 \%-80 \%$ of all cases of epistaxis are idiopathic, spontaneous bleeds without any proven precipitant or causal factor which is classified as primary epistaxis. A small proportion is due to a clear and

'Financial or Other Competing Interest': None.

Submission 04-12-2017, Peer Review 29-12-2017,

Acceptance 04-01-2018, Published 13-01-2018.

Corresponding Author:

Dr. Madhuri M. Gudikote,

No. 616, MIMS Girls Hostel,

MIMS Campus, Mandya-571401.

E-mail: madhuri5291@gmail.com

DOI: $10.14260 /$ jemds $/ 2018 / 66$

\section{(c) (i) $\$$}

definite cause such as trauma, surgery or anticoagulant overdose and has been classified as secondary epistaxis. The frequency of admission is greatest in the autumn and winter months, which correlates with fluctuations in environmental temperature and humidity. Onset of bleeding and hospital admission show a biphasic pattern with peaks in the morning and late evening. Adult pattern epistaxis is associated with the use of NSAIDs (antiplatelet aggregation effect). ${ }^{1}$ Aetiological associations have been found with consumption of alcohol. It is possible that hypertension causes arteriosclerotic nasal vascular changes that predispose hypertensives to increased susceptibility to epistaxis. ${ }^{3}$ Management of patient with epistaxis at any age group begins with resuscitating the patient, establishing the site of bleed, stopping the bleeding and treatment of the underlying cause. There is no definite protocol for the management of epistaxis, although various treatment methods are available for the management ranging from local pressure, topical vasoconstrictor, nasal packing, cauterisation (chemical/ electric), to embolisation or ligation. ${ }^{4}$ 
Hence, there is a need to identify the various risk factors in order to appropriately manage the condition and reduce the morbidity.

\section{MATERIALS AND METHODS}

This retrospective descriptive study was carried out in Department of Otorhinolaryngology, Mandya Institute of Medical Sciences (MIMS), Mandya, Karnataka, between January 2016 and December 2016 in patients who were admitted for epistaxis. A total of 47 cases admitted for epistaxis in 2016 were included in this study. Cases admitted for traumatic epistaxis and epistaxis following nasal surgeries were excluded from the study.

Case files of these patients were reviewed from the Medical Records Department of MIMS teaching hospital, Mandya and a unique case proforma was used to record parameters like demographics, month of presentation, trigger of bleeding, comorbid medical conditions, drug history, anterior rhinoscopy and endoscopic nasal examination findings, treatment modality, complications and length of hospital stay.

Patients with epistaxis admitted in the ENT ward were reviewed and vitals were recorded with special emphasis on blood pressure. Patients with high blood pressure were diagnosed to have accelerated hypertension and that as the cause of epistaxis. Physician's opinion was taken and vitals were stabilised.

Intravenous line was established in all patients with wide bore cannula. Initially, all the patients who presented with active bleeding were treated with anterior nasal packing using antibiotic soaked ribbon gauze, which was kept in-situ for 48 hours. Meanwhile, all these patients received intravenous antibiotics. Patients were evaluated with anterior rhinoscopy and nasal endoscopy to identify the site of bleeding.

All the patients had undergone routine investigations such as complete blood count, haemoglobin level, platelet count, random blood sugar, blood grouping. Coagulation profile such as prothrombin time, activated plasma thromboplastin time, and bleeding and clotting time was also performed. Computed tomography (CT) was done in selected cases to rule out neoplasms of nose and paranasal sinuses; and the nasopharynx. Additional investigations were also done based on history and clinical examination about the possible aetiology and comorbidity.

Nonsurgical treatment methods like application of topical vasoconstrictors such as oxymetazoline and xylometazoline nasal drops, topical haemocoagulase drops, anterior and posterior nasal packing and chemical cauterisation of the bleeder were done. Surgical treatment methods like the endoscopic electrocauterisation of the bleeder and the endoscopic sphenopalatine artery electrocoagulation were considered. All the patients were initially treated conservatively and surgical treatment was considered only when conservative method failed to control the epistaxis. Cause of epistaxis was considered after evaluation. When no cause was found, it was considered as idiopathic.

The collected data was entered in an Excel sheet and analysed using Epi-Info/SPSS software.

\section{RESULTS}

A total of 47 patients were admitted in ENT with epistaxis during the study period. The age ranged from 22 - 90 years with an average of 52.57 years. Among these $68.08 \%$ were males and $31.91 \%$ were females showing a male preponderance.

\section{MALES $\square$ FEMALES}

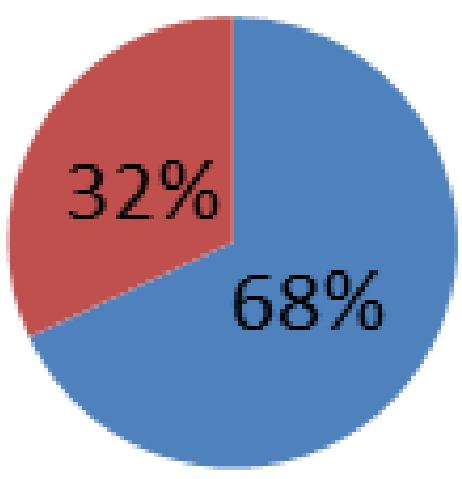

Figure 1. Distribution of Cases according to Gender

$65.95 \%$ of the patients presented to the hospital in the emergency room and $34.04 \%$ of the patients presented to the ENT outpatient department (OPD). This shows that epistaxis is one of the most common emergencies seen in ENT.

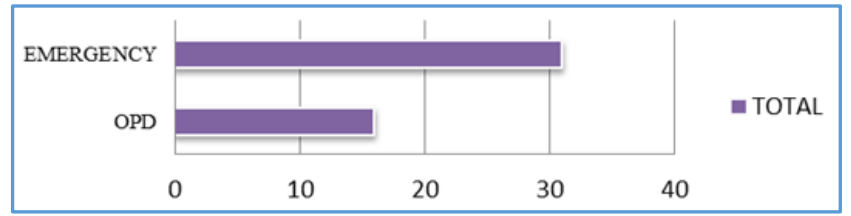

Figure 2. Presentation to Hospital

All the patients were admitted and discharged once the epistaxis was evaluated and controlled. The average length of stay of these patients in the hospital was 3.08 days.

\begin{tabular}{|c|c|c|}
\hline Causes & Total & Percentage \\
\hline Hypertension & 29 & 61.70 \\
\hline Idiopathic & 11 & 23.40 \\
\hline Liver disease & 5 & 10.63 \\
\hline Nasal mass & 1 & 2.12 \\
\hline Drug induced & 1 & 2.12 \\
\hline Total & $\mathbf{4 7}$ & $\mathbf{1 0 0}$ \\
\hline \multicolumn{3}{|c|}{ Table 1. Aetiology } \\
\hline
\end{tabular}

Patients were evaluated to know the cause of epistaxis. Patients in whom no cause could be found were considered as idiopathic (23.40\%). Patients who presented with hypertension were diagnosed to have epistaxis secondary to accelerated hypertension (61.70\%), which was the most common cause seen in this study. Patients with altered coagulation profile and liver function tests were chronic alcoholics suffering from chronic liver disease (10.63\%). There was one case of malignancy nasopharynx, who presented with epistaxis $(2.12 \%)$. There was one case of 
rheumatic heart disease on anticoagulant therapy, who presented with epistaxis $(2.12 \%)$.

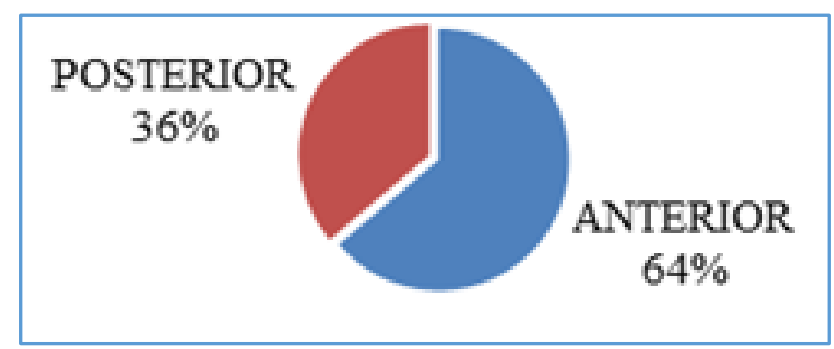

Figure 3. Type of Epistaxis

Depending on the site of bleeding, epistaxis can be divided into anterior and posterior epistaxis. Anterior epistaxis is more common and in this study 30 patients had anterior epistaxis (64\%) and 17 patients had posterior epistaxis (36\%).

\begin{tabular}{|c|c|c|}
\hline Season & Total & Percentage \\
\hline Winter & 18 & 38.29 \\
\hline Summer & 9 & 19.14 \\
\hline Monsoon & 8 & 17.02 \\
\hline Autumn & 12 & 25.53 \\
\hline \multicolumn{2}{|c|}{ Table 2. Season of Presentation } \\
\hline
\end{tabular}

In this study, majority of the patients presented with epistaxis during the winter season (38.29\%) followed by autumn season $(25.53 \%)$.

\begin{tabular}{|c|c|c|}
\hline Procedure & Total & Percentage \\
\hline Observation & 6 & 12.76 \\
\hline Anterior nasal packing & 38 & 80.85 \\
\hline $\begin{array}{c}\text { Anterior and posterior nasal } \\
\text { packing }\end{array}$ & 7 & 14.89 \\
\hline Chemical cautery & 3 & 6.38 \\
\hline Electrocautery & 9 & 19.14 \\
\hline SPA electrocoagulation & 1 & 2.12 \\
\hline Septoplasty & 1 & 2.12 \\
\hline \multicolumn{2}{|c|}{ Table 3. Management } \\
\hline
\end{tabular}

All the patients who presented with active bleed underwent anterior nasal packing 39/47 (82.97\%). Among them, epistaxis was controlled in 23 patients (48.93\%) with anterior nasal packing alone. 7 patients required posterior nasal packing, 9 patients required electrocautery for anterior bleed, 1 patient required sphenopalatine artery electrocoagulation when posterior nasal packing failed to control epistaxis; 8 patients did not have active bleed at presentation; 5 patients were under observation and 3 patients required chemical cautery. One patient underwent septoplasty when chemical cautery failed to control recurrent epistaxis. Epistaxis was controlled by conservative methods in $76.59 \%$ patients. One patient required transfusion of fresh frozen plasma for correction of coagulopathy. One case of malignancy nasopharynx was subjected to radiotherapy.

\section{DISCUSSION}

The aetiology of epistaxis in the majority of patients is idiopathic, followed in frequency by primary neoplasms and traumatic or iatrogenic causes. ${ }^{5}$ In present study, epistaxis secondary to accelerated hypertension $(61.70 \%)$ was the most common cause followed by epistaxis due to idiopathic cause. This is similar to a study by Canovas $\mathrm{M}$ et $\mathrm{al}^{6}{ }^{6}$ where hypertension accounted to $56 \%$. In a study by Iseh KR et al, ${ }^{7}$ hypertension as a cause for epistaxis accounted to $18 \%$. A study by Herkner $\mathrm{H}$ et $\mathrm{al}^{8}{ }^{8}$ found that active epistaxis was independently associated with history of hypertension. In a retrospective study by Terakura $\mathrm{M}$ et $\mathrm{al}, 9$ they found that persistent epistaxis was significantly more frequent in patients with hypertension than in those without. In studies done by Varshney $S$ et $\mathrm{al}^{2}$ and Parajuli $\mathrm{R}, 10$ hypertension was the second most common cause next to idiopathic cause.

The nasal cavity is extremely vascular. Terminal branches of the external and internal carotid arteries supply the mucosa of the nasal cavity with frequent anastomoses between these systems. The anterior nasal septum is the site of a plexus of vessels called Little's or Kiesselbach's area, which is supplied by both systems. The branching of the sphenopalatine artery when it enters the nasal cavity is a key point in understanding of the management of posterior nose bleeds. The maxillary sinus ostium serves as the dividing line between "anterior" and "posterior" epistaxis. ${ }^{5}$ Anterior epistaxis was more common than posterior epistaxis in this study, which is similar to a study by Parajuli R. ${ }^{10}$

The most common cause is spontaneous bleeding with or without hypertension, from small vessels along the nasal septum and superior margins of the nasal cavity. ${ }^{11}$ Elderly people commonly have comorbidities such as hypertension and diabetes mellitus which cause degenerative changes in blood vessels, making them more fragile which bleed easily on abrupt pressure changes such as straining during micturition and defecation in benign prostate hypertrophy and constipation respectively; excessive coughing in chronic obstructive pulmonary disease; and lifting heavy objects. ${ }^{12}$

The general pathophysiology of the disease may affect the tissues of the nose, as in recurrent or severe epistaxis secondary to a coagulopathy. Anticoagulants can precipitate epistaxis. The unique mucosal histology of the nose may make an otherwise minor pathologic process more severe and apparent, as seen in hereditary haemorrhagic telangiectasia. A systemic disease may affect the tissues of the nose as part of a symptom complex, as seen in Wegener's granulomatosis. ${ }^{11}$ Possible explanations for the relationship between case presentations according to season and temperature include increased use of forced air heating and potential increase in the frequency of URTIs (upper respiratory tract infections) during colder times. Some studies have also shown a decrease in coagulation in colder temperatures. ${ }^{13.14}$ In the present study majority of the patients presented with epistaxis during the winter season (38.29\%) followed by autumn (25.53\%), which is similar to other studies by Kodiya AM et al ${ }^{15}$ and Varshney $\mathrm{S}$ et al. ${ }^{2}$

The initial evaluation of the patient presenting with epistaxis should focus on evaluating the stability of the airway, initial control of the bleeding and stabilisation of vital signs with fluid replacement or blood transfusions. If the airway is deemed stable, non-surgical approaches for haemostasis should first be attempted. Local vasoconstrictors (i.e. epinephrine), either topical and/or injected may assist with haemostasis. If the site of bleeding is visible, its cauterisation may be possible. ${ }^{16}$ Cautery of the bleeding site can be performed chemically, electrically or with laser. ${ }^{17}$ 
Septoplasty is also performed in patients with a history of severe epistaxis caused by septal varices that develop from anterior cartilage deviation and the secondary interruption of lamellar airflow with resultant drying and irritation of the mucosa. ${ }^{11}$

In this study, one patient underwent septoplasty for control of recurrent epistaxis. A study by Parajuli R 10 also mentions about septoplasty in control of epistaxis.

Severe epistaxis should be treated initially by anteroposterior tamponade. If anterior tamponade fails, the dual balloon tube is introduced as far as the nasopharynx. The posterior balloon is inflated moderately and blocked in the choana. The anterior balloon is then inflated in the vestibule of the nostril to isolate the whole nasal fossa. ${ }^{18}$ In the present study $82.97 \%$ of the patients underwent anterior nasal packing, of which epistaxis was controlled with anterior nasal packing alone in $48.93 \%$. Epistaxis was controlled by conservative methods in majority of the patients $(76.59 \%)$, which is similar to many other studies.

Different types of surgery are possible: Endoscopic electrocautery, endonasal electrocoagulation of the sphenopalatine artery, ligation of the anterior ethmoidal artery, ligation of the posterior ethmoidal artery, ligating the internal maxillary artery (IMA), ${ }^{18}$ embolisation of the distal branches of the bilateral IMAs and ipsilateral distal branches of the facial artery. ${ }^{19}$

One of the patients in this study required fresh frozen plasma transfusion. No mortality was seen in this study.

\section{CONCLUSION}

Epistaxis is a common emergency condition in Otorhinolaryngology. Excluding trauma, hypertension and coagulopathy were the most common aetiological factors among the patients in whom aetiology was found. Nasal packing is the most conservative and effective method of controlling epistaxis in majority of the cases. Surgical treatment is only required when epistaxis is not controlled with conservative treatment methods.

\section{REFERENCES}

[1] McGarry GW. Epistaxis. Scott-Brown's Otorhinolaryngology. 7th edn. Vol. 2. Great Britain: Hodder Arnold 2008:1596-608.

[2] Varshney S, Saxena RK. Epistaxis: a retrospective clinical study. Indian J Otolaryngol Head Neck Surg 2005;57(2):125-9.

[3] Isezuo SA, Segun-Busari S, Ezunu E, et al. Relationship between epistaxis and hypertension: a study of patients seen in the emergency units of two tertiary health institutions in Nigeria. Niger J Clin Pract 2008;11(4):379-82.
[4] Klotz DA, Winkle MR, Richmon J, et al. Surgical management of posterior epistaxis: a changing paradigm. Laryngoscope 2002;112(9):1577-82.

[5] Simmen DB, Jones NS. Epistaxis. Cummings Otolaryngology Head and Neck Surgery. $6^{\text {th }}$ edn. Philadelphia: Saunders 2015:678-90.

[6] Monjas-Canovas I, Hernandez-Garcia I, Mauri-Barbera $\mathrm{J}$, et al. Epidemiology of epistaxes admitted to a tertiary hospital. Acta Otorrinolaringol Esp 2010;61(1):41-7.

[7] Iseh KR, Muhammad Z. Pattern of epistaxis in Sokoto, Nigeria: a review of 72 cases. Ann Afr Med 2008;7(3):107-11.

[8] Herkner H, Laggner AN, Mullner M, et.al. Hypertension in patients presenting with epistaxis. Ann Emerg Med 2000;35(2):126-30.

[9] Terakura M, Fujisaki R, Suda T, et al. Relationship between blood pressure and persistent epistaxis at the emergency department: a retrospective study. J Am Soc Hypertens 2012;6(4):291-5.

[10] Parajuli R. Evaluation of etiology and treatment methods for epistaxis: a review at a tertiary care hospital in Central Nepal. Article ID 283854, International J Otolaryngol 2015;2015:1-5.

[11] Flint PW, Haughey BH, Lund VJ, et al. Cummings Otolaryngology Head and Neck Surgery. $6^{\text {th }}$ edn. Philadelphia: Saunders 2015.

[12] Randall DA, Freeman SB. Management of anterior and posterior epistaxis. Am Fam Physician 1991;43(6):2007-14.

[13] Eccles R. An explanation for the seasonality of acute upper respiratory tract viral infections. Acta Otolaryngol 2002;122(2):183-91.

[14] Rundgren M, Engstrom M. A thromboelastometric evaluation of the effects of hypothermia on the coagulation system. Anesth Analg 2008;107(5):14658.

[15] Kodiya AM, Labaran AS, Musa E, et al. Epistaxis in Kaduna, Nigeria: a review of 101 cases. African Health Sciences 2012;12(4):479-82.

[16] McClurg SW, Carrau R. Endoscopic management of posterior epistaxis: a review. Acta Otorhinolaryngologica Italica 2014; 34(1):1-8.

[17] Razdan U, Raizada RM, Chaturvedi VN. Efficacy of conservative treatment modalities used in epistaxis. Indian J Otolaryngol Head Neck Surg 2004;56(1):20-2.

[18] Pollak JS, White RI. The use of cyanoacrylate adhesives in peripheral embolization. J Vasc Interv Radiol 2001;12(8):907-13.

[19] Krajina A, Chrobok V. Radiological diagnosis and management of epistaxis. Cardiovasc Intervent Radiol 2014;37(1):26-36. 